\title{
Effect of heat stress on physiological and yield contributing traits in wheat (Tritium aestivum L.)
}

\author{
Tanweer Fatah Abro ${ }^{1 *}$, Wahid Dino Sipio ${ }^{1}$, Zahoor Ahmed Soomro', \\ Abdul Wahid Baloch ${ }^{1}$, Wajid Ali Jatoi ${ }^{1}$, Ghulam Mustafa Bhanbhan ${ }^{2}$, \\ Abdul Hafeez Mastoi ${ }^{3}$, Khalil Ahmed Laghari ${ }^{4}$, Mohammad Arsal ${ }^{5}$ and \\ Mazhar Ali Mastoi ${ }^{1}$
}

1. Department of Plant Breeding \& Genetics, Sindh Agriculture University Tandojam-Pakistan

2. Sugarcane Research Institute Tandojam-Pakistan

3. Lasbela University of Agriculture Water and Marine sciences-Pakistan

4. Nuclear Institute of Agriculture, Tandojam, Pakistan-Pakistan

5. Oil seeds Institute ARI, Tandojam-Pakistan

*Corresponding author's email: fatahtanweer@yahoo.com

Citation

Tanweer Fatah Abro, Wahid Dino Spio, Zahoor Ahmed Soomro, Abdul Wahid Baloch, Wajid Ali Jatoi, Ghulam Mustafa Bhanbhan, Abdul Hafeez Mastoi, Khalil Ahmed Laghari, Mohammad Arsal and Mazhar Ali Mastoi. Effect of heat stress on physiological and yield contributing traits in wheat (Tritium aestivum L.). Pure and Applied Biology. Vol. 8, Issue 4, pp2343-2361. http://dx.doi.org/10.19045/bspab.2019.80181

Received: 02/04/2019 Revised: 21/06/2019

Accepted: 18/08/2019

Online First: 23/08/2019

\section{Abstract}

Heat stress is increasing drastically and has become a major threat to wheat production in various wheat growing regions. Exposure of wheat genotypes to temperatures above the critical threshold level during flowering and grain-filling stages can cause reproductive failure and grain yield reduction. To withhold this situation, a research was carried out on twenty bread wheat genotypes viz. AS-11, AS-12, AS-13, AS14, AS-15, AS-16, AS-17, AS-18, AS-19, AS-20, AS-21, AS-22, AS-23, AS-24, AS-25, AS-26, AS-27, AS-28, AS-29 and Chakwal-86 (check), at the Experimental Field, Nuclear Institute of Agriculture (NIA), Tandojam. The experiment was conducted in Randomized Complete Block Design having three replications during Rabi season, for evaluating the response of terminal heat stress in wheat genotypes. The analysis of variance revealed significant differences among the genotypes at both normal and high temperatures. Reduction in various traits was observed due to late planting, which indicated visible effects of high temperature on physio-yield traits. On the basis of average performance, tillers plant ${ }^{-1}$, spikelets spike $^{-1}$, grain yield plant ${ }^{-1}$, grains spike ${ }^{-1}$, grain weight of main spike ${ }^{-1}$ and biological weight plant $^{-1}$ showed reduction of 24.83, 7.1, 39.78, 14.87, 25.49 and 37.41, respectively under heat stress conditions. However, minimum reduction under heat stress was manifested in the wheat genotypes as AS-15, AS-26 and AS-13 for various traits, suggesting their presence of heat tolerance. Nonetheless, the advance lines AS-14 and AS-19 expressed maximum decline under heat stress displaying their susceptibility to heat stress conditions. The remaining genotypes exhibited moderate heat stress tolerance. Thus, the selected advance lines have great potential for heat tolerance and can be utilized for future breeding program.

Keywords: Bread wheat; Heat stress; Morpho-yield traits; Temperature 


\section{Introduction}

Wheat is widely grown crop adapted under cool growing environment. Although it is also grown under moderately high temperature $\left(25-32^{\circ} \mathrm{C}\right)$ for longer duration and very high temperature $\left(33-40{ }^{0} \mathrm{C}\right)$ for a shorter period are very common in subtropical environments of South East Asia [1]. Its production in hot areas is feasible but yield has been always declined due to heat stress, especially at the stage of anthesis and grain filling. Therefore heat stress is one the main abiotic stress causing significant yield loses of wheat crop in arid, semiarid, subtropical, and tropical regions of the world [2].

According to Halford et al. [3] the average global temperature is rising at the rate of $0.18^{\circ} \mathrm{C}$ every decade. It is estimated that the climate will also be affected by continuous increase in temperature and frequency of hot days will also increase. To withhold such critical situation, it is drastically needed to adopt heat tolerant varieties and to understand the mechanism of plant response to tolerate the extreme temperature and how tolerance can be improved.

High temperature stress during reproductive development termed as terminal heat stress. Studies suggest that optimal temperature for grain set and grain filling is between $19^{\circ} \mathrm{C}$ and $22^{\circ} \mathrm{C}$ in wheat [4]. The threshold temperature considered as the value of daily mean temperature, at which a detectable reduction in growth begins, is $26^{\circ} \mathrm{C}$ for wheat at post anthesis stage [5]. In wheat, terminal heat stress with ambient temperature $>30^{\circ} \mathrm{C}$, during reproductive development stage has been found to decrease productivity [6]. Accompanied with rising mean temperature as a result of global warming, high temperature at the time of grain filling affects grain production in many environments [7]. It is one of the major causes of yield reduction which affects more than 36 million hectares in temperate environments [8]. Both physiological and morphological traits like chlorophyll content, canopy temperature depression, photosynthetic rate, biomass, thousand grain weights, grain yield and yield associated traits are influenced by heat stress [8]. Grain yield and its quality are the principal characters of a cereal crop. They are complex quantitative characters, which are influenced by a number of yield contributing characters. Hence, the selection for desirable genotypes should not only be based on yield alone, but other yield components should also be considered. Heat stress, being a major environmental yield constraint, its severity relies upon its intensity, duration and stage of the crop [9]. The occurrence of heat stress at reproductive stage is more harmful than vegetative stage as it causes direct effects on grain number, size of grain, dry weight and finally yield of the crops [10]. It has been reported that, the sowing dates in terms of change in temperature are critical for determining appropriate crop yields. Therefore, the present study was conducted to evaluate the performance of new wheat advance lines along with check variety, to estimate the effects of early and terminal heat stresses on yield and its associated traits.

\section{Material and methods}

The experiment comprising of twenty wheat genotypes was carried out at the experimental farm of Nuclear Institute of Agriculture, Tandojam. The experimental material were sown in Randomized Complete Block Design (RCBD) with three replications in two sowing dates viz. normal planting $\left(15^{\text {th }}\right.$ November, 2016) and late planting $\left(15^{\text {th }}\right.$ December, 2016) as to determine the effect of heat stress on reduction of yield and its components in late sowing wheat. The experiment was conducted during Rabi season 2016-2017. Daily minimum and maximum temperature were recorded throughout the season. From each replication, five plants were tagged randomly for collecting necessary data under field 
conditions and some observations were recorded under the laboratory condition.

Treatments: 02

T1 Normal sowing (15 $5^{\text {th }}$ November $)$

T2 Late sowing (15 ${ }^{\text {th }}$ December $)$

Genotypes: 20

1. AS 11

2. AS 12

3. AS 13

4. AS 14

5. AS 15

6. AS 16

7. AS 17

8. AS 18

9. AS 19

10. AS 20

11. AS 21

12. AS 22

13. AS 23

14. AS 24

15. AS 25

16. AS 26

17. AS 27

18. AS 28

19. AS 29

20. Chakwal 86 (check)

Traits recorded:

1. Tillers plant ${ }^{-1}$
2. Spikelets spike ${ }^{-1}$

3. Grain yield plant ${ }^{-1}(\mathrm{~g})$

4. Grains spike ${ }^{-1}$

5. Grain weight of main spike ${ }^{-1}(\mathrm{~g})$

6. Biological weight $\operatorname{plant}^{-1}(\mathrm{~g})$

7. Flag leaf area (\%)

8. Relative water content (\%)

Results

Analysis of variance

The analysis of variance for mean squares (Table 1) indicated that heat stress has significant effect on tillers plant ${ }^{-1}$, spikelets spike $^{-1}$, grain yield plant ${ }^{-1}$, grains spike ${ }^{-1}$, grains weight of main spike ${ }^{-1}$, and biological weight plant $^{-1}$. Thus, indicating that morphological characters can be best indicator for wheat breeder for selecting heat tolerant varieties. The mean performance from analysis of variance for genotype $\mathrm{x}$ treatment interaction was also significant for all the studied traits. The significance of genotype $\mathrm{x}$ treatment interaction expressed that genotypes performed variably over the stress conditions. The present interaction can assist wheat breeder for identifying the best high yielding varieties on one or more reliable heat tolerant indicators.

Table 1. Mean squares from analysis of variance for various morphological traits of wheat genotypes grown under non- stress and heat stress conditions

\begin{tabular}{|c|c|c|c|c|c|}
\hline Traits & $\begin{array}{l}\text { Replication } \\
\quad(\mathrm{D} . \mathrm{F}=2)\end{array}$ & $\begin{array}{c}\text { Genotype } \\
\text { (G) } \\
\text { (D.F=19) }\end{array}$ & $\begin{array}{c}\text { Treatment } \\
(\mathbf{T}) \\
(\mathrm{D} . \mathbf{F}=1)\end{array}$ & $\begin{array}{c}\text { G x T } \\
(\mathbf{D . F}=19)\end{array}$ & $\begin{array}{c}\text { Error } \\
(\mathrm{D} . \mathrm{F}=38)\end{array}$ \\
\hline Tillers plant $^{-1}$ & 1.612 & $12.7498 * *$ & $98.645^{* *}$ & $1.0566 * *$ & 0.1470 \\
\hline Spikelets spike $^{-1}$ & 0.137 & $4.901 * *$ & $49.152 *$ & $0.621^{*}$ & 0.163 \\
\hline $\begin{array}{c}\text { Grain yield } \\
\text { plant }^{-1}\end{array}$ & 0.862 & $85.623^{* *}$ & $2671.171 * *$ & $3.543 * *$ & 1.061 \\
\hline Grains spike $^{-1}$ & 1.413 & $304.373 * *$ & $3248.961 * *$ & $16.801 * *$ & 0.852 \\
\hline $\begin{array}{l}\text { Grains weight } \\
\text { spike }^{-1}\end{array}$ & 0.013 & $1.187 * *$ & $12.390 * *$ & $0.129 * *$ & 0.0226 \\
\hline $\begin{array}{c}\text { Biological } \\
\text { weight plant }{ }^{-1}\end{array}$ & 0.033 & $205.722 * *$ & $5981.232 * *$ & $16.433^{* *}$ & 0.633 \\
\hline Flag leaf area & 14.783 & 83.051 ** & $3473.733^{* *}$ & $32.822 * *$ & 4.641 \\
\hline $\begin{array}{c}\text { Relative water } \\
\text { content }\end{array}$ & 1.641 & $544.713 * *$ & $4523.712^{* *}$ & $24.511 * *$ & 3.143 \\
\hline
\end{tabular}

$* * *=$ significant at 1 and $5 \%$ of probability levels, respectively 


\section{Mean performance of different traits grown under stress and non-stress conditions \\ Tillers plant ${ }^{-1}$}

In non-stress conditions, tillers plant ${ }^{-1}$ ranged from 4.53 to 10.4 , while under heat stress condition, it ranged from 3.5 to 9.6. The average of tillers plant ${ }^{-1}$ of all the genotypes in non-stress condition was 7.71 and under the heat stress condition was 5.87, thus averagely $24.68 \%$ reduction was caused by terminal heat stress. The lowest decrease percentage however was recorded by AS 15 (7.69\%), closely followed by AS 26 and AS $13(9.93$ and $10.36 \%)$, respectively, under the heat stress condition. The maximum loss was observed in AS 14 with decrease percentage of (47.44\%), followed by AS 29 (47.07\%). The higher tillers plant $^{-1}$ exhibited by genotype AS 15 was 10.4 and the lowest by AS 234.53 in normal condition, however in heat stress conditions, the maximum tillers plant $^{-1}$ was obtained from AS 15 (9.06) and the less by AS 23 (3) (Table 2, Fig. 1).

\section{Spikelets spike $\mathrm{e}^{-1}$}

In normal condition, the range of spikelets spike $^{-1}$ was counted as 20.26 to 23.06 , while in heat stress varieties recorded 17.93 to 22.46 spikelets spike ${ }^{-1}$ (Table 2, Fig. 2). On an average, the genotypes produced 21.63 spikelets spike ${ }^{-1}$ in non-stress condition and 20.1 under heat stress conditions. The reduction of 7.1 averagely noticed among the genotypes due to heat stress. The lowest decline in spikelets spike ${ }^{-1}$ was observed in AS 15 (2.60\%), followed by AS 26 and AS 13 (3.43\% and $3.95 \%)$ respectively, in heat stress condition. The highest reduction was recorded in AS 14 (13.45\%), closely followed by AS 23 (13.04\%) in heat stress condition. The highest number of spikelets was counted AS $15(23.06 \%)$ and the lowest grain was counted in AS 14 (20.26) under non-stress condition. The maximum grains spike $^{-1}$ was recorded in AS 15 (22.46) and minimum number of grains in AS 18 (17.93) in heat stress condition. 
Table 2. Mean performance of tillers plant $^{-1}$ and spikelets spike ${ }^{-1}$ for different wheat genotypes grown under non-stress and heat stress conditions

\begin{tabular}{|c|c|c|c|c|c|c|}
\hline \multirow{2}{*}{ Genotypes } & \multicolumn{2}{|c|}{ Tiller plant $^{-1}$} & \multirow{2}{*}{$\begin{array}{c}\text { R.D. } \\
\%\end{array}$} & \multicolumn{2}{|c|}{ Spikelets spike $^{-1}$} & \multirow{2}{*}{$\frac{\text { R.D. }}{\%}$} \\
\hline & Non-stress & Heat stress & & Non-stress & Heat stress & \\
\hline AS 11 & 9.73 & 7.86 & 19.21 & 21.73 & 20.23 & 7.04 \\
\hline AS 12 & 7.21 & 5.73 & 20.41 & 20.26 & 18.46 & 8.88 \\
\hline AS 13 & 9.26 & 8.34 & 10.36 & 22.02 & 21.13 & 3.95 \\
\hline AS 14 & 6.66 & 3.53 & 47.44 & 21.33 & 18.46 & 13.45 \\
\hline AS 15 & 10.42 & 9.62 & 7.69 & 23.06 & 22.46 & 2.60 \\
\hline AS 16 & 8.61 & 5.93 & 31.04 & 23.04 & 21.22 & 7.82 \\
\hline AS 17 & 7.53 & 6.61 & 12.35 & 21.93 & 20.21 & 7.88 \\
\hline AS 18 & 7.26 & 5.33 & 26.58 & 20.61 & 17.93 & 12.96 \\
\hline AS 19 & 5.81 & 4.26 & 26.55 & 22.04 & 19.66 & 10.63 \\
\hline AS 20 & 8.86 & 6.41 & 27.76 & 21.46 & 20.33 & 5.26 \\
\hline AS 21 & 5.53 & 3.73 & 32.54 & 20.63 & 19.53 & 5.19 \\
\hline AS 22 & 8.06 & 5.33 & 33.87 & 22.53 & 21.02 & 6.79 \\
\hline AS 23 & 4.53 & 3.01 & 33.77 & 21.02 & 18.26 & 13.04 \\
\hline AS 24 & 7.81 & 6.73 & 13.71 & 21.26 & 20.33 & 4.37 \\
\hline AS 25 & 7.42 & 5.24 & 29.72 & 21.53 & 20.11 & 7.10 \\
\hline AS 26 & 9.66 & 8.73 & 9.93 & 22.43 & 21.66 & 3.43 \\
\hline AS 27 & 5.73 & 4.41 & 23.21 & 22.21 & 20.86 & 6.03 \\
\hline AS 28 & 7.53 & 6.06 & 19.52 & 21.26 & 20.26 & 4.70 \\
\hline AS 29 & 8.53 & 4.62 & 46.07 & 21.33 & 20.13 & 5.62 \\
\hline $\begin{array}{c}\text { Chakwal-86 } \\
\text { (check) }\end{array}$ & 8.26 & 6.21 & 24.93 & 21.22 & 20.06 & 5.37 \\
\hline Mean & 7.71 & 5.87 & 24.83 & 21.63 & 20.12 & 7.1 \\
\hline $\begin{array}{c}\text { LSD (5\%) } \\
\text { (G) }\end{array}$ & \multicolumn{2}{|c|}{0.44} & & \multicolumn{2}{|c|}{0.50} & \\
\hline $\begin{array}{c}\text { LSD (5\%) } \\
(\mathrm{T})\end{array}$ & \multicolumn{2}{|c|}{0.13} & & \multicolumn{2}{|c|}{0.15} & \\
\hline $\begin{array}{c}\text { LSD }(5 \%) \\
(\mathbf{G} \times \mathbf{T})\end{array}$ & \multicolumn{2}{|c|}{0.62} & & \multicolumn{2}{|c|}{0.71} & \\
\hline
\end{tabular}

${ }^{*}=$ Relative decrease due to heat stress treatments 


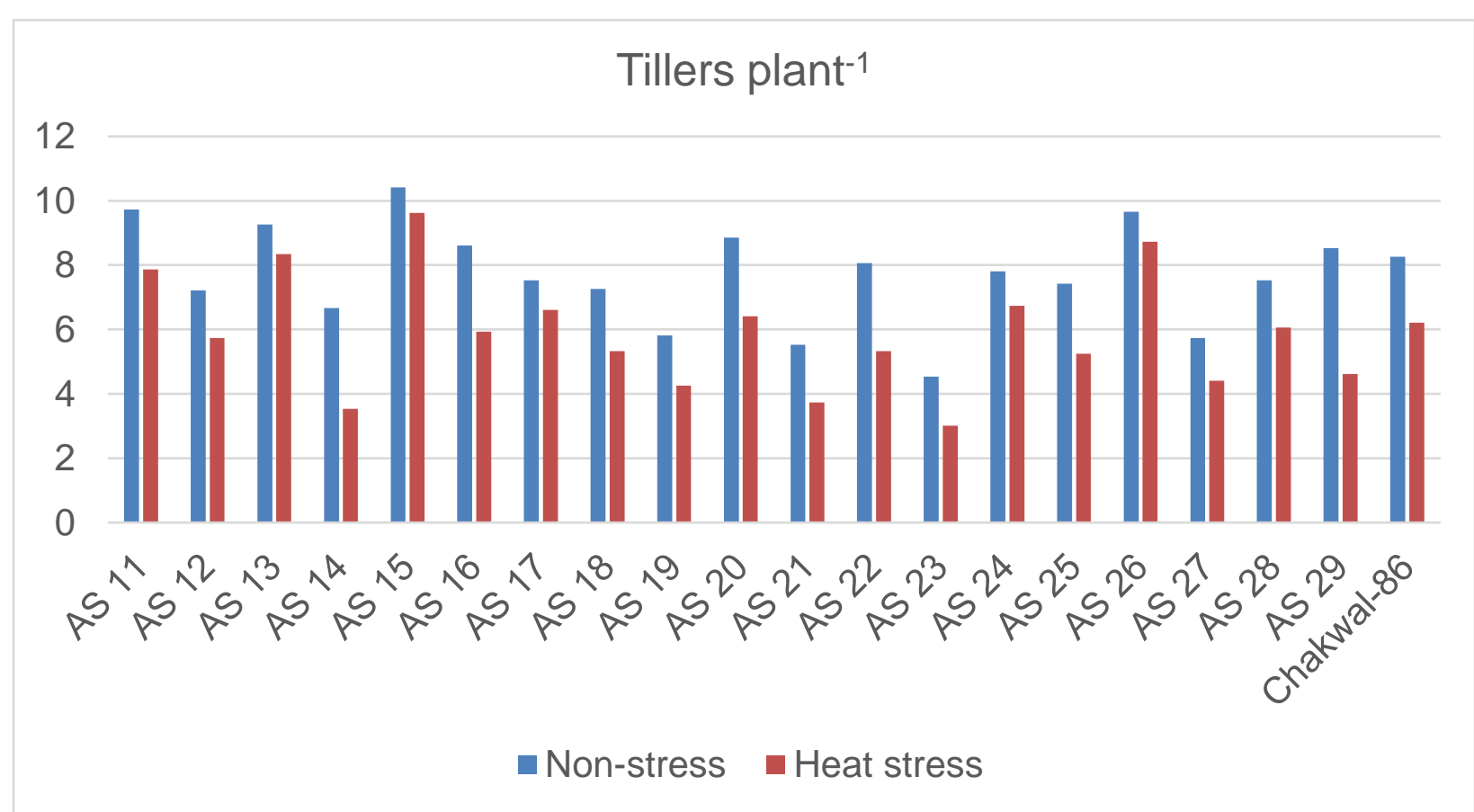

Figure 1. Mean performance of tillers plant $^{-1}$ for different wheat genotypes grown under non-stress and heat stress conditions

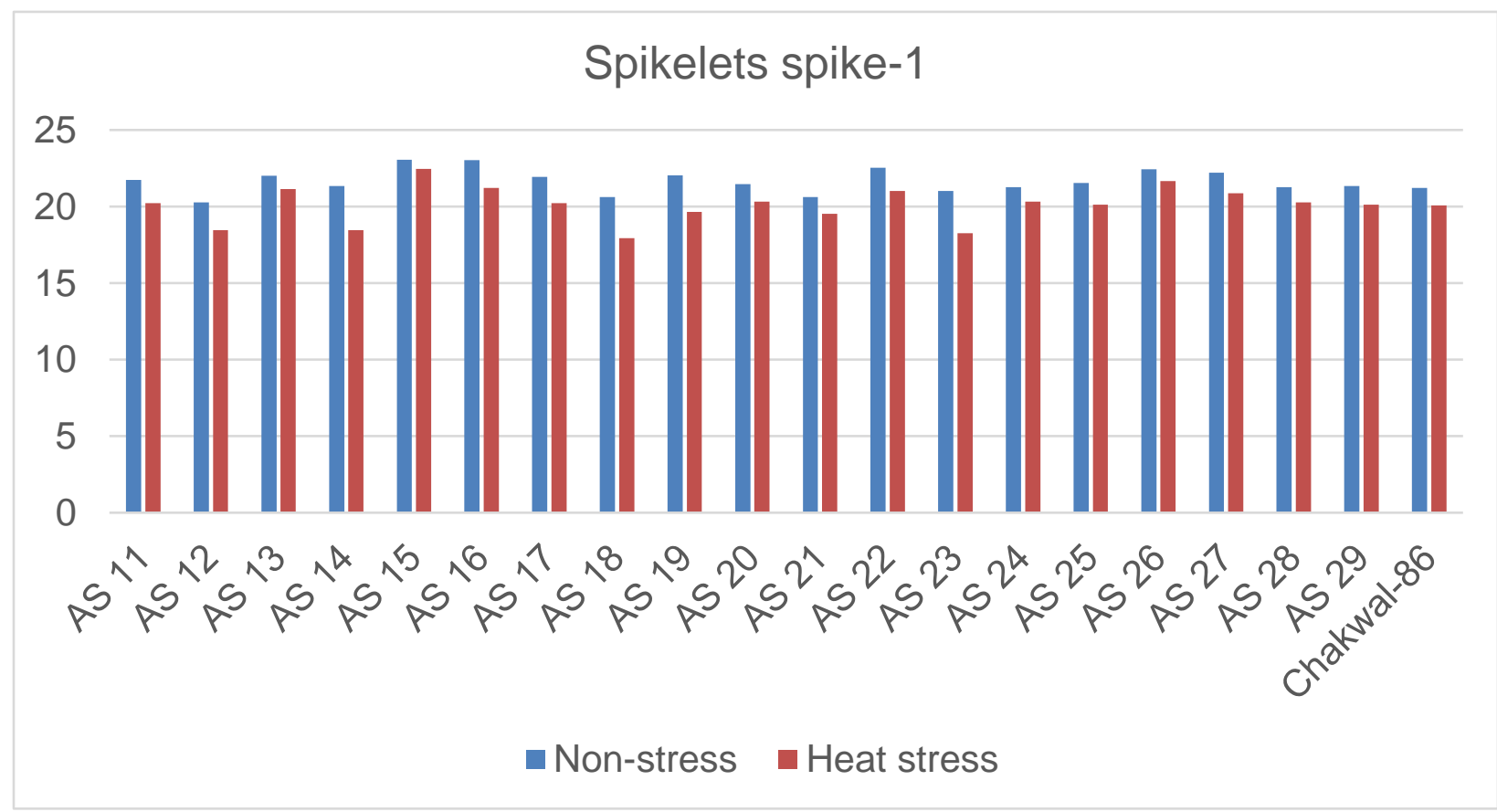

Figure 2. Mean performance of spikelets spike $\mathrm{e}^{-1}$ for different wheat genotypes grown under non-stress and heat stress conditions 


\section{Grain yield plant ${ }^{-1}$}

In our experiment, grain yield plant ${ }^{-1}$ ranged from 17.25 to $31.89 \mathrm{~g}$, in non-stress condition, while in heat stress condition it varied from 8.91 to $24.09 \mathrm{~g}$ (Table 3, Fig. 3). The mean performance of all the genotypes in nonstress condition was $23.25 \mathrm{~g}$, however in terminal heat stress condition, it was $14.17 \mathrm{~g}$. On an average, $39.78 \%$ loss in grain yield plant $^{-1}$ occurred due to terminal heat stress. The greatest performance was observed in AS 15 with minimum reduction of $(24.55 \%)$, followed by AS 26 and AS 13 (30.08\% and $32.84 \%$ ) respectively under heat stress condition. The highest relative decrease percentage was displayed by AS 14 (48.48\%), followed by AS $19(46.30 \%)$ in terminal heat stress condition. The maximum grain yield plant ${ }^{-1}$ was opted by AS 15 $(31.89 \mathrm{~g})$ and the minimum by AS $14(17.25 \mathrm{~g})$ in non-stress condition, whereas in heat stress condition the highest grain yield plant ${ }^{-1}$ was also manifested by AS $15(24.09 \mathrm{~g})$ and the lowest by AS 14 (8.91g).

\section{Grains spike ${ }^{-1}$}

In non-stress condition, the range of grains spike $^{-1}$ was counted as 60.46 to 81.13 , whereas in heat stress conditions, the varieties recorded 47.86 to 76.72 grains spike $^{-1}$ (Table 3, Fig. 4). On the basis of an average, the genotypes produced 70.88 grains spike $^{-1}$ in non-stress condition and 60.35 under heat stress conditions. The reduction of 14.87 averagely noticed among the genotypes due to heat stress. The lowest decline in grains spike ${ }^{-1}$ was observed in AS 15 (5.43\%), followed by AS 13 and AS 16 (9.29\% and $9.34 \%$ ) respectively, under heat stress condition. The highest reduction was recorded in AS 14 (25.37\%), followed by AS $28(22.79 \%)$ in heat stress condition. The highest grain number was counted by AS 15 (81.13) and the lowest grain was counted in AS 23 (60.46) under non-stress condition. The maximum grains spike ${ }^{-1}$ was recorded in AS 15 (76.72) and minimum number of grains in AS 14 (47.86) in heat stress conditions. 
Table 3. Mean performance of grain yield plant $^{-1}$ and grains spike sor $^{-1}$ different wheat genotypes grown under non-stress and heat stress conditions

\begin{tabular}{|c|c|c|c|c|c|c|}
\hline \multirow{2}{*}{ Genotypes } & \multicolumn{2}{|c|}{ Grain yield plant $^{-1}$} & \multirow{2}{*}{$\begin{array}{c}\text { R.D. }{ }^{*} \\
\%\end{array}$} & \multicolumn{2}{|c|}{ Grains spike $^{-1}$} & \multirow{2}{*}{$\begin{array}{c}\text { R.D. } \\
\%\end{array}$} \\
\hline & Non-stress & Heat stress & & Non-stress & Heat stress & \\
\hline AS 11 & 22.73 & 13.19 & 41.97 & 67.41 & 53.43 & 20.72 \\
\hline AS 12 & 25.93 & 15.13 & 41.65 & 64.26 & 55.42 & 13.78 \\
\hline AS 13 & 27.07 & 18.18 & 32.84 & 79.01 & 71.66 & 9.29 \\
\hline AS 14 & 17.25 & 8.91 & 48.48 & 64.13 & 47.86 & 25.37 \\
\hline AS 15 & 31.89 & 24.09 & 24.45 & 81.13 & 76.72 & 5.43 \\
\hline AS 16 & 25.35 & 15.71 & 38.06 & 78.14 & 70.84 & 9.34 \\
\hline AS 17 & 22.01 & 13.42 & 39.02 & 75.18 & 65.83 & 12.43 \\
\hline AS 18 & 23.63 & 14.78 & 37.45 & 74.21 & 63.52 & 14.39 \\
\hline AS 19 & 18.42 & 9.89 & 46.30 & 66.66 & 53.82 & 19.29 \\
\hline AS 20 & 26.95 & 17.36 & 35.58 & 76.83 & 64.54 & 15.99 \\
\hline AS 21 & 19.46 & 10.98 & 43.57 & 74.61 & 66.46 & 10.91 \\
\hline AS 22 & 24.11 & 14.97 & 37.90 & 65.44 & 53.06 & 14.33 \\
\hline AS 23 & 18.79 & 10.28 & 45.29 & 60.46 & 53.35 & 11.75 \\
\hline AS 24 & 22.94 & 13.17 & 42.58 & 69.62 & 55.29 & 20.56 \\
\hline AS 25 & 23.63 & 13.18 & 44.22 & 66.66 & 54.82 & 17.79 \\
\hline AS 26 & 28.29 & 19.78 & 30.08 & 80.66 & 72.23 & 10.48 \\
\hline AS 27 & 18.25 & 11.46 & 37.20 & 73.13 & 63.23 & 13.53 \\
\hline AS 28 & 21.97 & 11.98 & 45.47 & 70.82 & 54.66 & 22.79 \\
\hline AS 29 & 23.16 & 13.03 & 43.73 & 61.83 & 51.73 & 16.29 \\
\hline Chakwal-86 (check) & 23.31 & 14.01 & 39.87 & 67.56 & 58.83 & 13.01 \\
\hline Mean & 23.25 & 14.17 & 39.78 & 70.88 & 60.35 & 14.87 \\
\hline LSD (5\%) (G) & \multicolumn{2}{|c|}{1.14} & & \multicolumn{2}{|c|}{1.07} & \\
\hline LSD (5\%) (T) & \multicolumn{2}{|c|}{0.36} & & \multicolumn{2}{|c|}{0.34} & \\
\hline LSD (5\%) (GxT) & \multicolumn{2}{|c|}{1.62} & & \multicolumn{2}{|c|}{1.52} & \\
\hline
\end{tabular}

${ }^{*}=$ Relative decrease due to heat stress treatments 


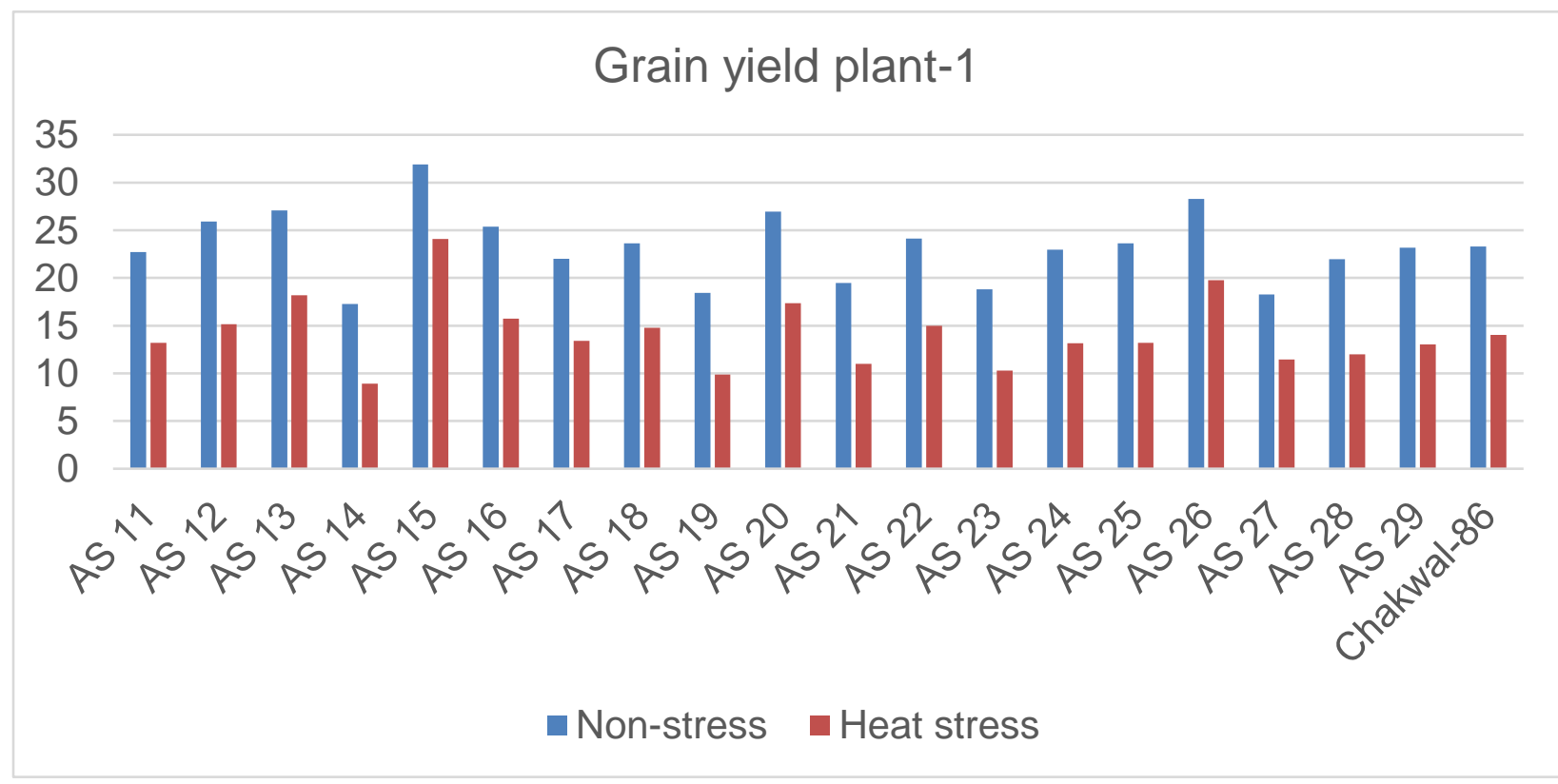

Figure 3. Mean performance of grain yield plant $^{-1}$ for different wheat genotypes grown under non-stress and heat stress conditions

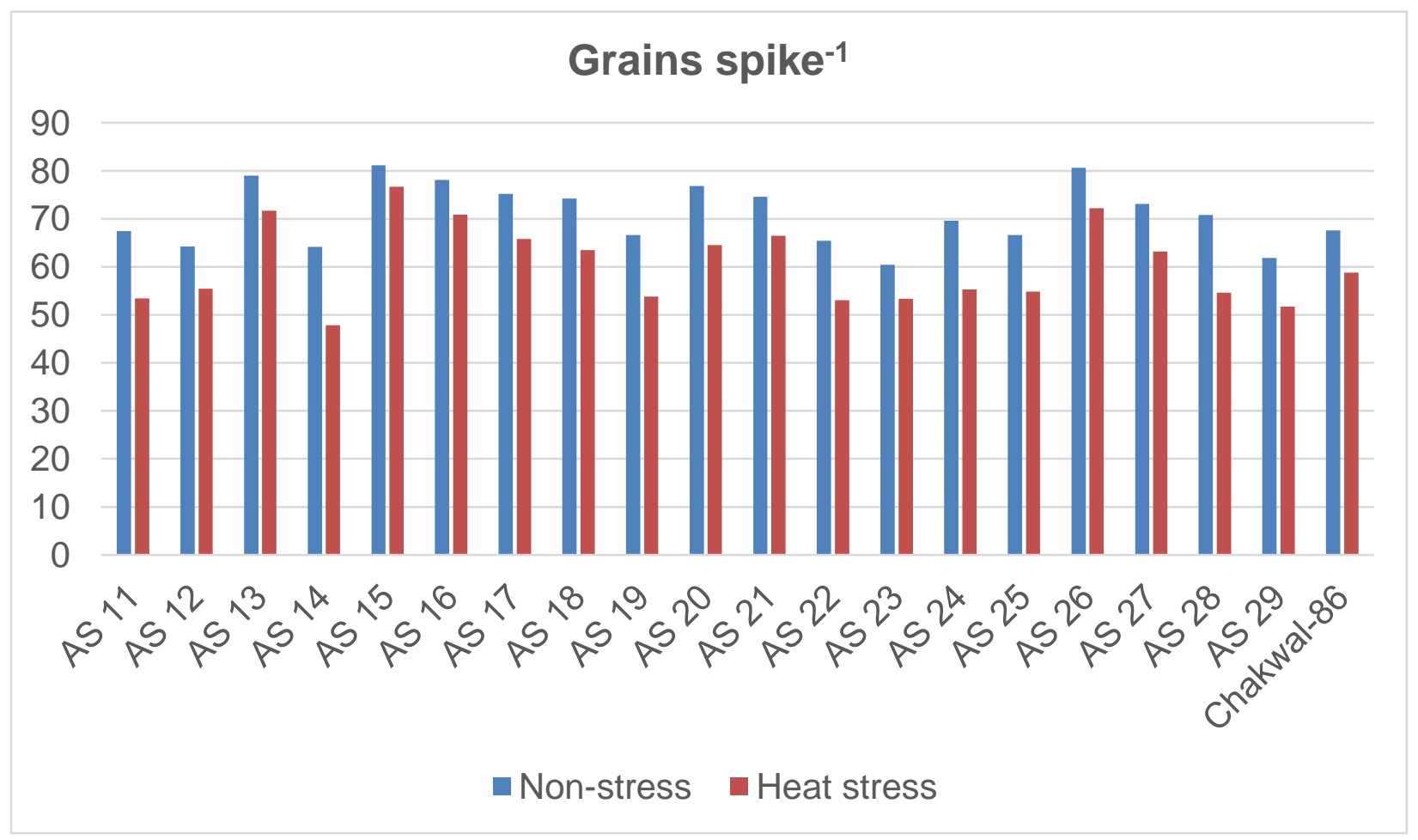

Figure 4. Mean performance of grains spike $^{-1}$ for wheat genotypes grown under non-stress and heat stress conditions 


\section{Grains weight of main spike ${ }^{-1}(g)$}

According to the results of grain weight of main spike ${ }^{-1}$, the highest value for main spike yield was recorded in AS 15 (3.66 g) spike ${ }^{-1}$, while lowest value was observed in AS 14 $(2.02 \mathrm{~g})$ at normal temperature (Table 4, Fig. 5). Maximum main spike yield was observed in AS 15 (3.04 g) spike ${ }^{-1}$ and minimum main spike yield was observed in AS 14 (1.06 g) in high temperature condition. However, decrease percent for main spike yield among genotypes ranged from 7.10 to $47.52 \%$. Genotype AS 15 showed less reduction $(7.10 \%)$ in main spike yield.

\section{Biological weight plant $^{-1}$}

In non-stress conditions, the biological weight plant ${ }^{-1}$ ranged from 46.73 to $64.01 \mathrm{~g}$, while under heat stress condition, it ranged from 25.04 to $53.33 \mathrm{~g}$. The average biological yield of all the genotypes in non-stress condition was $55.24 \mathrm{~g}$ and under the heat stress condition was $40.35 \mathrm{~g}$, in this way, averagely $37.41 \%$ reduction was brought about by terminal heat stress. The lowest decrease percentage however was recorded by AS 15 (16.71\%), closely followed by AS 26 and AS 13 (17.97 and 18.62\%), respectively, under the heat stress condition. The maximum loss was observed in AS 14 with decrease percentage of (46.50\%), followed by AS 19 (42.91\%). The higher biological weight plant $^{-1}$ exhibited by genotype AS 15 was $64.01 \mathrm{~g}$ and lowest by AS $1446.73 \mathrm{~g}$ in non- stress condition, while in heat stress conditions, the greater biological weight plant ${ }^{-1}$ was obtained from AS $15(53.33 \mathrm{~g})$ and the less by AS $14(25.04$ g) (Table 4, Fig. 6 ). 
Table 4. Mean performance of grain weight spike $\mathrm{s}^{-1}$ and biological weight plant $^{-1}$ for different

\begin{tabular}{|c|c|c|c|c|c|c|}
\hline \multirow{2}{*}{ Genotypes } & \multicolumn{2}{|c|}{ Grain weight spike ${ }^{-1}$} & \multirow{2}{*}{$\begin{array}{c}\text { R.D. } \\
\%\end{array}$} & \multicolumn{2}{|c|}{ Biological weight plant ${ }^{-1}$} & \multirow{2}{*}{$\begin{array}{c}\text { R.D. } \\
\%\end{array}$} \\
\hline & Non-stress & Heat stress & & Non-stress & Heat stress & \\
\hline AS 11 & 2.81 & 1.79 & 36.29 & 51.03 & 37.63 & 26.27 \\
\hline AS 12 & 2.71 & 2.31 & 14.76 & 58.04 & 41.66 & 28.27 \\
\hline AS 13 & 2.88 & 2.51 & 12.84 & 55.33 & 45.01 & 18.62 \\
\hline AS 14 & 2.02 & 1.06 & 47.52 & 46.73 & 25.04 & 46.50 \\
\hline AS 15 & 3.66 & 3.43 & 7.10 & 64.01 & 53.33 & 16.71 \\
\hline AS 16 & 2.78 & 2.39 & 14.02 & 60.33 & 46.72 & 22.55 \\
\hline AS 17 & 2.23 & 1.92 & 14.79 & 54.04 & 42.31 & 21.66 \\
\hline AS 18 & 2.57 & 2.19 & 14.78 & 56.66 & 45.01 & 20.49 \\
\hline AS 19 & 2.06 & 1.15 & 44.17 & 47.33 & 27.02 & 42.91 \\
\hline AS 20 & 2.81 & 2.41 & 13.92 & 61.33 & 48.83 & 20.34 \\
\hline AS 21 & 2.84 & 1.71 & 40.14 & 47.33 & 31.11 & 34.52 \\
\hline AS 22 & 2.66 & 2.03 & 23.68 & 54.33 & 39.62 & 27.11 \\
\hline AS 23 & 2.64 & 1.83 & 30.68 & 49.51 & 35.63 & 28.08 \\
\hline AS 24 & 2.69 & 1.73 & 35.68 & 60.66 & 44.61 & 26.47 \\
\hline $\operatorname{AS~} 25$ & 2.52 & 2.02 & 19.84 & 58.31 & 43.02 & 26.24 \\
\hline AS 26 & 3.11 & 2.81 & 9.67 & 57.33 & 47.04 & 17.97 \\
\hline AS 27 & 2.54 & 1.57 & 38.18 & 48.03 & 37.11 & 22.91 \\
\hline AS 28 & 2.89 & 2.02 & 30.10 & 60.05 & 38.03 & 36.66 \\
\hline AS 29 & 2.41 & 1.49 & 37.91 & 51.33 & 31.02 & 39.60 \\
\hline Chakwal-86 (check) & 2.77 & 2.11 & 23.82 & 63.53 & 48.01 & 24.40 \\
\hline Mean & 2.67 & 2.02 & & 55.24 & 40.35 & \\
\hline LSD (5\%) (G) & \multicolumn{2}{|c|}{0.17} & 25.49 & \multicolumn{2}{|c|}{0.93} & 37.41 \\
\hline LSD (5\%) $(\mathrm{T})$ & \multicolumn{2}{|c|}{0.05} & & \multicolumn{2}{|c|}{0.29} & \\
\hline $\operatorname{LSD}(5 \%)(\mathbf{G} \times \mathbf{T})$ & \multicolumn{2}{|c|}{0.24} & & \multicolumn{2}{|c|}{1.32} & \\
\hline
\end{tabular}

wheat genotypes grown under non-stress and heat stress conditions

*=Relative decrease due to heat stress treatment 


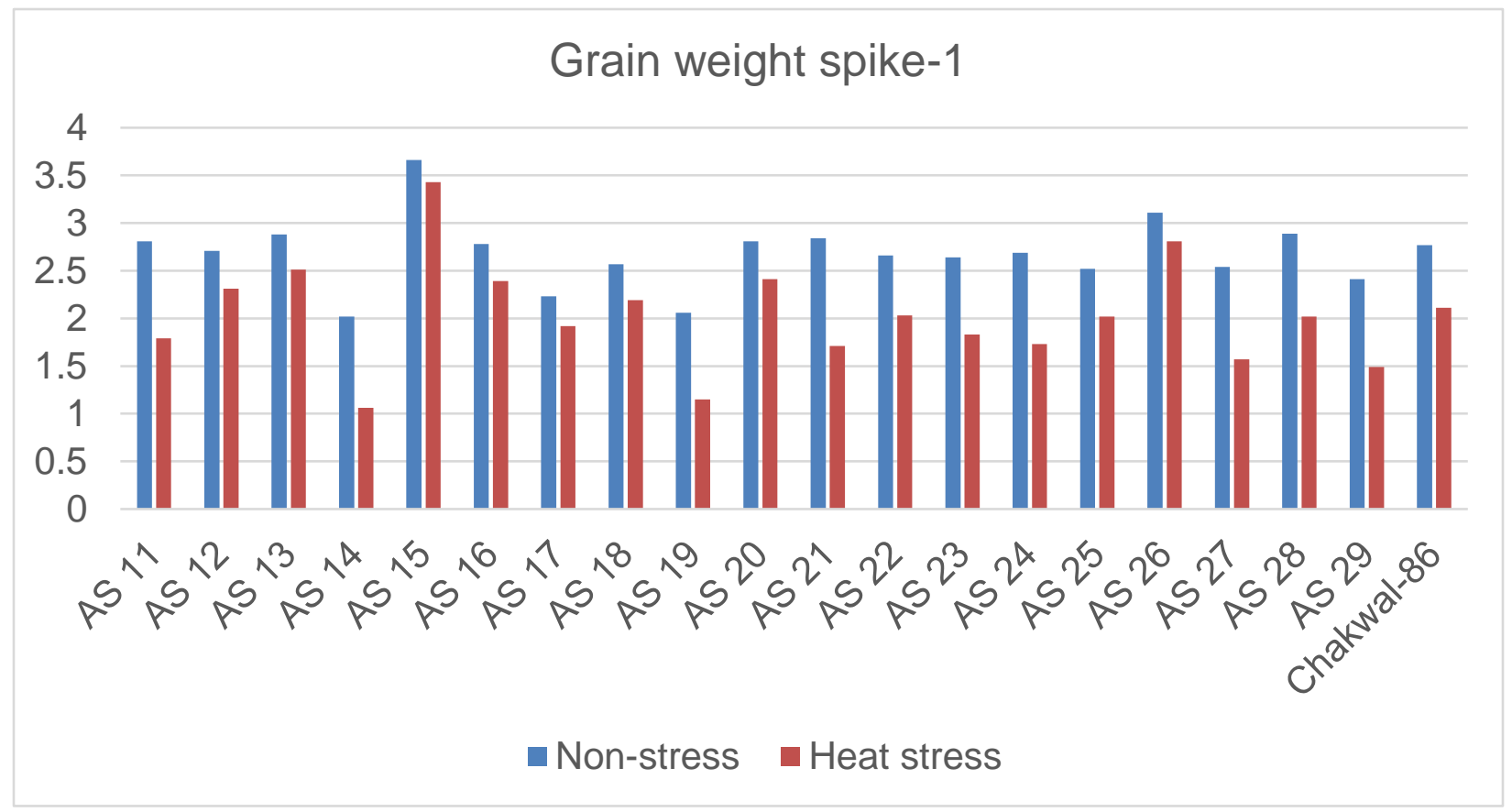

Figure 5. Mean performance of grain weight spike $^{-1}$ for different wheat genotypes grown under non-stress and heat stress conditions

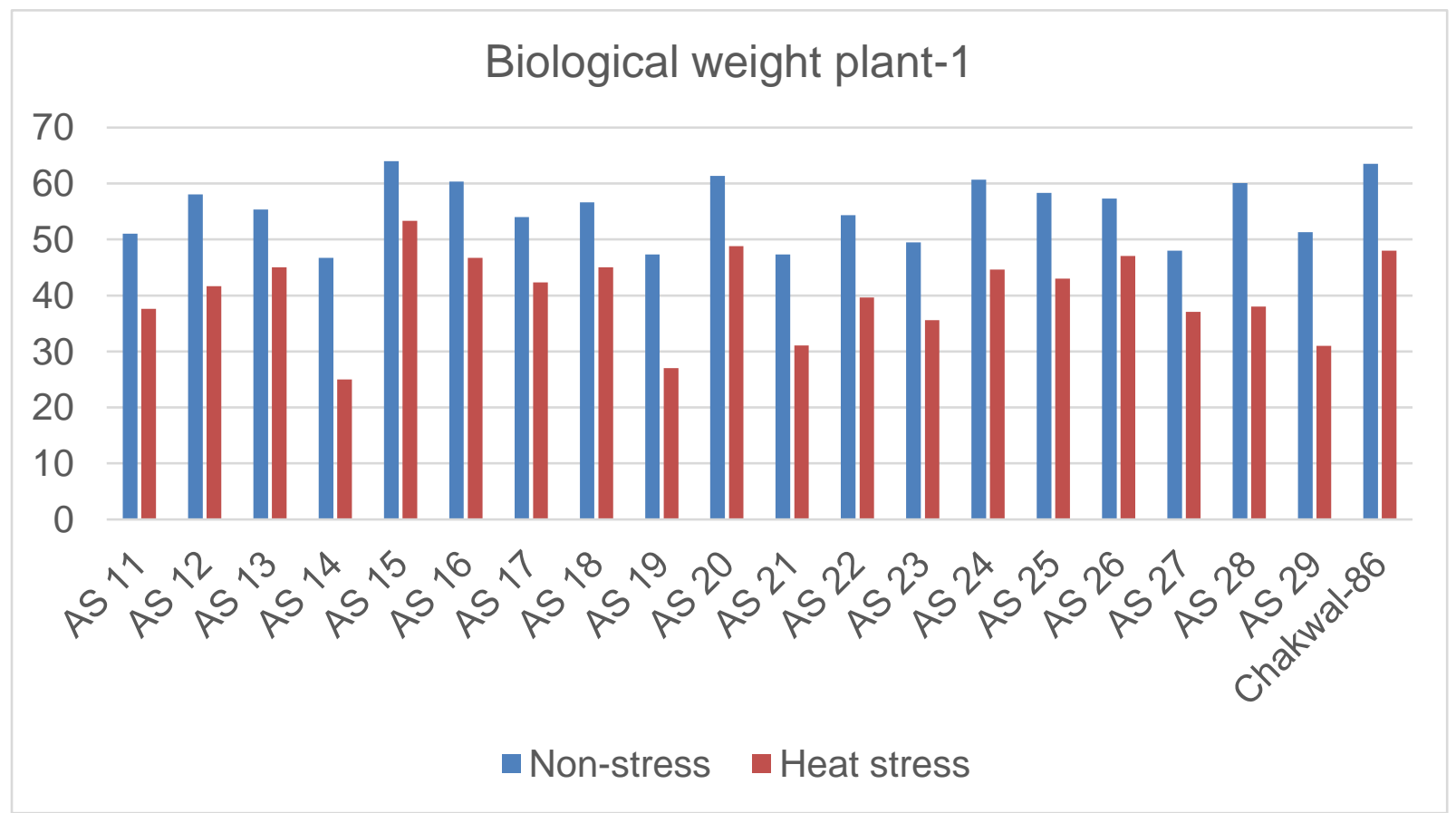

Figure 6. Mean performance of biological weight plant $^{-1}$ for wheat genotypes grown under non-stress and heat stress conditions 


\section{Flag leaf area $\left(\mathrm{cm}^{2}\right)$}

The flag leaf area ranged from 28.91 to 47.33 $\mathrm{cm}^{2}$ under non-stress conditions and 19.93 to $33.43 \mathrm{~cm}^{2}$ in heat stress conditions. Nonetheless, the average of all the genotypes was $36.03 \mathrm{~cm}^{2}$ in non-stress conditions and $25.78 \mathrm{~cm}^{2}$ under heat stress conditions. On an average, heat stress caused $28.05 \%$ decline (Table 5, Fig. 7). The highest loss in leaf area was observed in AS 14 (50.52\%), followed by AS 19 (39.95\%) under heat stress conditions. The lowest decline was noted in AS 15 (13.61\%), followed by AS 13 and AS $16(17.16$ and $17.63 \%)$ in heat stress conditions. The maximum flag leaf was found in AS $14\left(47.33 \mathrm{~cm}^{2}\right)$ under non-stress condition. The greatest flag leaf was noticed in AS 16 (33.43) and the lowest in AS 21 (19.93) due to heat stress.

\section{Relative water content (\%)}

The range of relative water content was from 70.25 to $90.46 \%$ under sown crop, whereas in late sowing dates, it ranged from 54.67 to
$84.91 \%$ (Table 5). The mean performance of all the genotypes grown under non-stress conditions was $76.37 \%$, while in heat stress conditions, it was $63.88 \%$. Heat stress caused a decline of 16.67 on an average, over the genotypes (Table 5, Fig. 8). The best performance of relative water content under the heat stress condition was given by genotype AS 15 with the lowest decrement percentage of $6.13 \%$. After AS 15, the highest performance was expressed by genotypes AS 26 and AS 13 with lower relative decline of $8.16 \%$ and $10.03 \%$, respectively. The maximum reduction 22.22\%, however was recorded in AS 14, which was followed by AS $2826.41 \%$ in terminal heat stress condition. In non-stress conditions, the greatest value was noted in genotype AS 15 (90.46\%) and the lowest value was expressed by AS 28 (70.25\%), whereas in heat stress conditions, the highest percentage of decline was recorded in AS 15 (84.91\%) and the lowest in AS 28 (51.69\%). 
Table 5. Mean performance for relative water content $(\%)$ and flag leaf area $(\mathrm{cm})$ of wheat genotypes grown under non-stress and heat stress conditions

\begin{tabular}{|c|c|c|c|c|c|c|}
\hline \multirow{2}{*}{ Genotypes } & \multicolumn{2}{|c|}{ Relative water content \% } & \multirow{2}{*}{$\begin{array}{c}\text { R.D. } \\
\%\end{array}$} & \multicolumn{2}{|c|}{ Flag leaf area } & \multirow{2}{*}{$\begin{array}{c}\text { R.D. }{ }^{*} \\
\%\end{array}$} \\
\hline & Non-stress & Heat stress & & Non-stress & Heat stress & \\
\hline AS 11 & 72.47 & 64.7 & 10.72 & 34.76 & 26.83 & 22.81 \\
\hline AS 12 & 78.12 & 67.64 & 13.41 & 29.32 & 21.37 & 27.11 \\
\hline AS 13 & 83.72 & 75.32 & 10.03 & 36.87 & 30.54 & 17.16 \\
\hline AS 14 & 70.29 & 54.67 & 22.22 & 43.07 & 21.31 & 50.52 \\
\hline AS 15 & 90.46 & 84.91 & 6.13 & 34.61 & 29.84 & 13.78 \\
\hline AS 16 & 75.38 & 61.31 & 18.66 & 40.59 & 33.43 & 17.63 \\
\hline AS 17 & 71.54 & 64.29 & 10.13 & 38.37 & 28.48 & 26.39 \\
\hline AS 18 & 74.94 & 59.21 & 20.99 & 34.97 & 25.73 & 26.42 \\
\hline AS 19 & 73.14 & 57.8 & 20.97 & 47.33 & 28.42 & 39.95 \\
\hline AS 20 & 80.83 & 67.86 & 16.04 & 34.88 & 27.66 & 20.69 \\
\hline AS 21 & 73.92 & 59.1 & 20.04 & 30.86 & 19.93 & 35.41 \\
\hline AS 22 & 76.52 & 66.22 & 13.46 & 36.75 & 22.67 & 38.31 \\
\hline AS 23 & 71.69 & 57.62 & 19.62 & 32.64 & 21.01 & 35.63 \\
\hline AS 24 & 71.92 & 57.73 & 19.73 & 28.91 & 20.79 & 28.08 \\
\hline AS 25 & 73.31 & 61.14 & 16,60 & 40.49 & 28.15 & 30.47 \\
\hline AS 26 & 88.78 & 81.53 & 8.16 & 32.23 & 26.14 & 18.89 \\
\hline AS 27 & 80.66 & 69.59 & 13.72 & 37.8 & 25.01 & 33.83 \\
\hline AS 28 & 70.25 & 51.69 & 26.41 & 32.13 & 25.02 & 22.12 \\
\hline AS 29 & 79.33 & 66.58 & 16.07 & 37.73 & 26.83 & 28.88 \\
\hline Chakwal-86 (check) & 72.33 & 58.55 & 19.12 & 36.45 & 26.6 & 27.02 \\
\hline Mean & 76.37 & 63.88 & 16.67 & 36.03 & 25.78 & 28.05 \\
\hline LSD $(5 \%)(G)$ & \multicolumn{2}{|c|}{2.01} & & \multicolumn{2}{|c|}{2.26} & \\
\hline $\operatorname{LSD}(5 \%)(\mathrm{T})$ & \multicolumn{2}{|c|}{0.63} & & \multicolumn{2}{|c|}{0.71} & \\
\hline LSD (5\%) (G x T) & \multicolumn{2}{|c|}{2.84} & & \multicolumn{2}{|c|}{3.19} & \\
\hline
\end{tabular}

${ }^{*}=$ Relative decrease due to heat stress treatments 


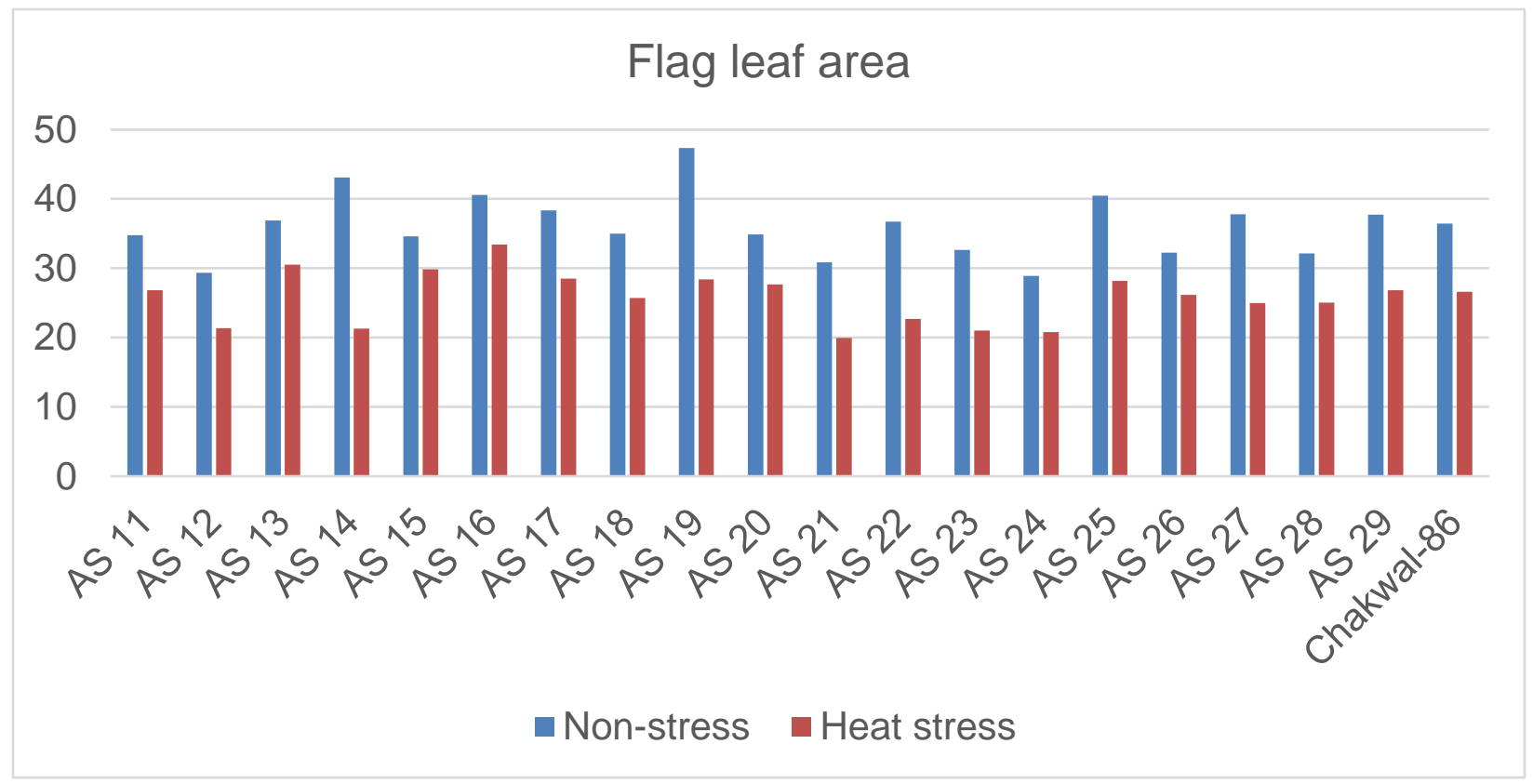

Figure 7. Mean performance of flag leaf area $\left(\mathrm{cm}^{2}\right)$ for different wheat genotypes grown under non-stress and heat stress conditions

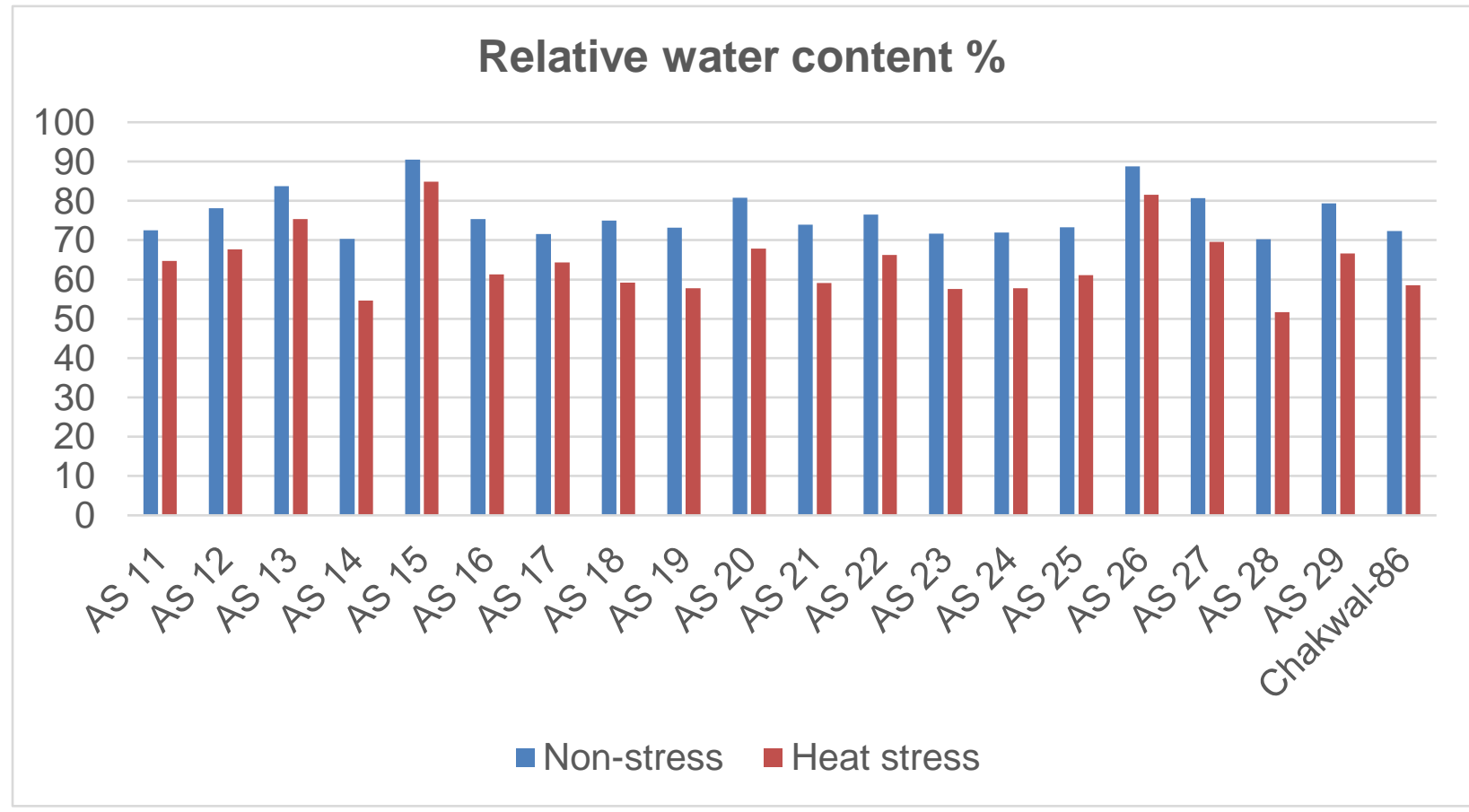

Figure 8. Mean performance of relative water content \% for wheat genotypes grown under non-stress and heat stress conditions 


\section{Discussion}

Heat stress is increasing at an alarming rate and reducing wheat production at a large scale. To determine that, at what extent wheat production is influencing, a detailed study was conducted to determine the effects of heat on newly developed advance wheat lines. In tillers plant ${ }^{-1}$, an average, $24.68 \%$ reduction was caused by terminal heat stress. The lowest decrease percentage however was recorded by AS 18 (3.58\%), closely followed by AS 11 and AS 15 (8.94 and $12.88 \%$ ), respectively, under the heat stress conditions. The maximum loss was observed in AS 14 with decrease percentage of (47.44\%), followed by AS 29 (47.07\%). In non-stress conditions, tillers plant ${ }^{-1}$ ranged from 4.53 to 10.4 , while under heat stress conditions, it ranged from 3 to 9.6. The higher tillers plant 1 exhibited by genotype AS 15 (10.4) and lowest by AS 23 (4.53) in non- stress conditions, whereas in heat stress conditions, the greater tillers plant ${ }^{-1}$ was obtained from AS 15 (9.06) and the less by AS 23 (3) (Table 2). Spikelets spike ${ }^{-1}$ is also a main character contributing towards increase in yields. As spikelets spike ${ }^{-1}$ increase ultimately number of the grain spike ${ }^{-1}$ will increase, resulting in higher grain yield plant ${ }^{-1}$. Maximum number of spikelets spike ${ }^{-1}$ was recorded in AS 15 (23.06) and minimum spikelets spike ${ }^{-1}$ was observed in AS 12 (20.26) at normal temperature. At high temperature stress, maximum number of spikelets spike ${ }^{-1}$ was recorded in AS 15 (22.46) and less spikelets spike $^{-1}$ exhibited in AS 23 (18.26). The decrease percent for number of spikelets spike ${ }^{-1}$ among genotypes ranged from 2.60 to $13.45 \%$. The genotype AS 14 and AS 18 showed the highest reduction (13.46 and $12.96 \%)$. However, the genotypes AS 15, AS 26 and AS 13 exhibited less reduction in number of spikelets spike ${ }^{-1}(2.60,3.43$ and $3.95 \%$ ), respectively. Considering the reduction percentage for spikelets spike ${ }^{-1}$, the present results showed valuable results under stress condition. Hence, those genotypes showing low reduction in number of spikelets spikes $^{-1}$ can be used as genetic stock for future breeding program. These results are in accordance with Irshad et al. [11]. Heat stress caused a decline of $40.04 \%$ averagely under the heat stress condition. The best performance was showed by AS 15 with minimum decrease of $24.45 \%$, followed by AS 26 and AS 13 (30.08 and $32.84 \%$ ), respectively. Whereas, the lowest performance was recorded by AS 14, followed by AS 19 with increased reduction of (48.48 and $46.30 \%)$ in grain yield plant ${ }^{-1}$ under heat stress conditions. In normal conditions, harvest index ranged 31.89 to $17.25 \mathrm{~g}$, whereas under the heat stress conditions, it ranged from 8.91 to $24.09 \mathrm{~g}$. Grains spike $^{-1}$ is also a key character in wheat breeding; it directly involves enhancing the grain yield plant $^{-1}$. Heat stress caused a decline of $14.87 \%$ averagely, in all the varieties grown under late sowing condition (Table 3). The highest reduction was observed in AS 14 (25.37\%), followed by AS $28(22.79 \%)$ under heat stress conditions. The lowest reduction was noticed in AS 15 $(5.43 \%)$, closely followed by AS 13 and AS 26 (9.29 and $10.39 \%$, respectively) under heat stress conditions. In normal conditions, grains spike ${ }^{-1}$ ranged from 60.46 to 81.13 , while in heat stress conditions, it ranged from 47.86 to 71.66 . The present results are in agreement of Hanson [12] who found significant difference in number of grain spike $^{-1}$ with different sowing dates. The results of Hanson [12] further revealed that greater number of grains spike ${ }^{-1}$ can be due to favorable temperature at the stage of seed development and maximum number of branches plant ${ }^{-1}$ with more productive spikes. Abd El-Majeed [13] and El-Ameen [14] noticed huge reduction in grain numbers because of late sowing and temperature stress. These findings were also supported by Hamam [15] who found $18.13 \%$ decline in 
grains number per spike due to terminal heat stress. Grain weight spike ${ }^{-1}$ is a key trait in wheat breeding, because it directly influence with grain yield plant ${ }^{-1}$. Heat stress during the grain filling period resulted in reduced grain development, ultimately decreased the grains weight in wheat crop [16]. For grain weight spike $^{-1}$, the highest value was recorded in AS 15 (3.66 g) spike ${ }^{-1}$, while lowest value was recorded for AS 14 (2.02 g) at normal temperature. Considering the high temperature, maximum value for main spike yield was observed in AS 15 (3.04 g) spike ${ }^{-1}$ and minimum was observed in AS 14 (1.06 g). The decrease percent for main spike yield among genotypes ranged from 7.10 to 47.52 $\%$. The genotype AS 15 showed less reduction $(7.10 \%)$ in main spike yield, indicating that these genotypes have great potential towards high temperature tolerance. High temperature reduces the grain filling period, which cause reduction in grain weight. Mumtaz et al. [17] Menshawy [18] and Khokhar et al. [19] found that early sowing wheat give higher grain weight spike ${ }^{1}$ as compared to late sowing wheat which may be due to longer grain filling duration in early planting and exemption from terminal heat stress. Our results are in agreement with Laghari et al. [20] who also reported $45.83 \%$ reduction in grain weight due to terminal heat stress. With respect to biological weight plant $^{-1}$, wheat genotypes showed different response for this trait at various planting dates. Maximum biological weight plant $^{-1}$ was observed in AS 15 (64 g) and minimum biological weight plant $^{-1}$ was observed in AS 14 (46.73 g) at normal temperature. At high temperature, the maximum biological weight plant $^{-1}$ was observed in AS 15 (53.3 g) and minimum biological weight plant $^{-1}$ was observed in AS 14 (25 g). The decrease percent for biological weight plant ${ }^{-1}$ among genotypes ranged from 16.71 to $46.50 \%$. The genotypes AS 14 and AS 19 showed the highest reduction $(46.50$ and $42.91 \%$,) in biological weight plant $^{-1}$, respectively. However, minimum reduction was noticed in AS $1516.71 \%$, followed by AS $26(17.97 \%)$ and AS 13 (18.62\%), under heat stress. Irfaq [21] Laghari et al. [20] Hossain et al. [22] and Alam et al. [23] reported reduction in the biological weight plant $^{-1}$ in all the wheat genotypes grown under heat stress condition in their experiments. Their results also support our findings that terminal heat stress is a major constraint in the development of flag leaf area. Dabi et al. [24] found that heat stress caused by late sowing significantly decreased the flag leaf area. On an average, heat stress caused decline of $28.05 \%$ in flag leaf area. The minimum relative decrease was however recorded in AS 15 (13.61\%), followed by AS 13 and AS 16 (17.16 and $17.63 \%)$, respectively under high temperature. The maximum reduction nevertheless was measured in AS 14 and AS 19 (50.52 and $39.95 \%)$, respectively in heat stress condition. In the optimum temperature, flag leaf area ranged from 28.91 to $47.33 \mathrm{~cm}^{2}$, while in heat stress conditions, it ranged from 19.93 to $33.43 \mathrm{~cm}^{2}$ (Table 6). Terminal heat stress caused a reduction of $16.67 \%$ averagely under late sowing date (Table 6). Nonetheless, maximum reduction was noticed in AS 14 (23.64\%), followed by AS $19(22.34 \%)$ in heat stress condition. Whereas, minimum reduction was recorded in AS $15(6.13 \%)$ followed by AS 26 and AS $13(8.16 \%$ and $10.03 \%$, respectively) under heat stress condition. The highest relative water content was measured in genotype AS $15(90.46 \%)$ under the both non-stress as well as in the heat stress $(84.91 \%)$ conditions. The lowest relative water content was observed in genotype AS 14 in non-stress (70.29\%) as well as in heat stresses $(53.67 \%)$ conditions.

\section{Authors' contributions}

Conceived and designed the experiments: TF Abro \& WD Sipio, Performed the experiments: ZA Soomro \& WD Sipio, Analyzed the data: AW Baloch, WA Jatoi \& 
GM Bhanbhan, Contributed materials/ analysis/ tools: AH Mastoi, KA Laghari \& M Arsal, Wrote the paper: TF Abro \& MA Mastoi.

\section{Acknowledgment}

The authors wish to acknowledge to the Director, Nuclear Institute of Agriculture, Tandojam for providing facilities in the experimental field to carry out the present research work.

\section{References}

1. Paulsen GM (1994). High temperature response of crop plants. In: Physiology and determination of crop yield. ASACCSA-SSSA. Madison WI pp 365-389.

2. Ashraf M \& Harris PJC (2005). Abiotic stresses plant resistance through breeding and molecular approaches. Food Products Press. USA.

3. Halford NG (2009). New insights on the effects of heat stress on crops. $J$ Exp Bot 60(3): 4215-4216.

4. Porter JR \& Gawith M (1999). Temperatures and the growth and development of wheat: a review. Euro $J$ Agro 10: 23-36.

5. Suryavanshi P \& Buttar GS (2016). Mitigating terminal heat stress in wheat. Int J Bio res St Man 7(1): 142-150.

6. Khajuria P, Singh AK \& Singh R (2016). Effect of heat stress on grain weight in bread wheat. Ind J App Res 6(1): 323327.

7. Hays DB \& Mason RE (2007). Wheat production in stressed environments. Springer, Dordrecht.

8. Bala S, Asthir B \& Bains NS (2014). Effect of terminal heat stress on yield and yield attributes of wheat. Ind J App Res 4(6): 2249-2250.

9. Wahid A, Gelani S, Ashraf M \& Foolad MR (2007). Heat tolerance in plants: An overview. Env Exp Bot 61(5): 199- 223.

10. Wollenweber B, Porter JR \& Schellberg J (2003). Lack of interaction between extreme high-temperature events at vegetative and reproductive growth stages in wheat. J Agro Crop Sci 189(2): $142-150$.

11. Irshad M, Khaliq I, Khan AS \& Ali A (2012). Genetic studies for some agronomic Traits in spring wheat under heat stress, Pak J Agri Sci 49(1): 20762082.

12. Hanson B (2001). Planting rate influence on yield and agronomic traits of hard red spring wheat in north eastern North Dakota. Langdon Res. Ext. Center NDSU Agri. Report I.

13. Abd El-Majeed, AM, Mousa SA \& Abd El-Kareem AA (2005). Effect of heat stress on some agronomic traits of bread wheat (Triticum aestivum L.) genotypes under Upper Egypt conditions. J Agri Res Dev 19(3): 4-16.

14. El Ameen T (2012). Stability analysis of selected wheat genotypes under different environment conditions in Upper Egypt. Afric J Agri Res 34(1): 4838-4844.

15. Hamam KA, Khaled AGA \& Zakariya MM (2015). Genetic stability and diversity in yield components of some wheat genotypes through seasons and heat stress under different location. $\mathrm{J} P l$ Prod Monsoura Univ 6(3): 39-370.

16. Guilioni L \& Lecoeur J (2013). High tempreture and water deficit may reduce seed number in field pea purely by decreasing plant growth rate. Funct $\mathrm{Pl}$ Biol 30(6): 1151-1164.

17. Mumtaz MZ, Aslam M, Nasrullah HM, Akhtar M \& Ali B (2015). Effect of various sowing dates on growth, yield and yield components of different wheat Genotypes. Am.Eurasian J Agri \& Environ Sci 15(11): 2230-2234.

18. Menshawy AMM (2007). Evaluation of some early bread wheat genotypes under different sowing dates: 1. Earliness characters. Egypt J Pl breed 11(4): 2540 . 
19. Khokhar, Z, Hussain I, Khokhar B \& Sohail M (2010). Effect of planting date on yield of wheat genotypes in Sindh. Pak. J Agri Res 23(3-4): 103-107.

20. Laghari, KA, Sial MA \& Arain MA (2012). Effect of high temperature stress on grain yield and yield components of wheat (Triticum aestivum L.). Sci. Tech. Dev 31(2): 83-90.

21. Irfaq $M$, Muhammad $T$, Amin $M$ \& Jabbar A (2005). Performance of yield and other agronomic characters of four wheat genotypes under heat stress. Int $J$ Bot 1(2): 124-127.

22. Hossain M, Sikara AZ, Saifuzamana MJ, Silvab ATD, Lozovskaya MV \& Akhtar MM (2013). Evaluation of growth yield, relative performance and heat susceptibility of eight wheat (Triticum aestivum L.) genotypes grown under heat stress. Int J Pl Prod 7(3): 615-636.

23. Alam MN, Bodruzzaman M, Hossain MM \& Sadekuzzaman M (2014). Growth performance of spring wheat under heat stress conditions. Int J Agro Agri Res 4(6): 91-103.

24. Dabi A, Mekbib F \& Desalegn T (2016). Estimation of genetic and phenotypic correlation coefficients and path analysis of yield and yield contributing traits of bread wheat (Triticum aestivum L.) genotypes. Int $J$ Nat Res Ecol Manag 1(4): $145-154$ 